\title{
Interactions between propionate and amino acid metabolism in isolated sheep hepatocytes
}

\author{
BY C. DEMIGNÉ, C. YACOUB, C. MORAND AND C. RÉMÉSY \\ INRA Laboratoire des Maladies Metaboliques, Centre de Recherches, Theix-F-63122, Ceyrat, \\ France
}

(Received 9 February 1990 - Accepted 13 July 1990)

\begin{abstract}
The purpose of the present study was to evaluate the contribution of various substrates to glucose synthesis in isolated sheep hepatocytes, and more specifically to quantify the contribution of propionate to gluconeogenesis. Liver cells from fed sheep have a very high capacity for propionate utilization and conversion into glucose. The glucogenicity of lactate or amino acids was very low in hepatocytes from fed sheep, but was significantly increased in hepatocytes from starved animals. Amino acids such as alanine or glutamine were characterized by a substantial utilization towards ureogenesis, whereas their conversion to glucose was very low. Propionate utilization and conversion into glucose was inhibited by butyrate, ammonia and especially ethanol (by up to $80 \%$ ). Ethanol promoted a striking accumulation of intracellular malate in hepatocytes incubated with propionate (reaching $14.9 \mu \mathrm{mol} / \mathrm{g}$ cell) and led to a depletion of phosphoenolpyruvate; ethanol inhibition could be counteracted by pyruvate. Propionate and butyrate enhanced ureogenesis from ammonia in ruminant liver cells but their effects were not additive. Propionate also elicited a marked increase in cellular concentrations of phosphoserine and serine, particularly in the presence of ammonia; such effects could influence phospholipid metabolism in the liver. These findings emphasize the contribution of propionate, compared with the other glucogenic substrates, to glucose synthesis in ruminants and point to the possibilities of modulation of the glucogenicity of propionate by various substrates which may be present in portal blood.
\end{abstract}

Gluconeogenesis: Hepatocytes: Propionate: Amino acids: Sheep

Ruminants generally absorb only small amounts of glucose from the alimentary tract and, thus, rely on hepatic gluconeogenesis for much of their glucose supply. The chief precursor of glucose in fed animals is propionate, which arises essentially from microbial fermentation in the rumen. The rate of glucose synthesis is highest in fed animals, decreasing during fasting (Bergman et al. 1966). This contrasts with the non-ruminant, where fasting stimulates gluconeogenesis. In vivo, propionate uptake by the liver is generally quantitative but its metabolic fate may be modified by other substrates (e.g. ammonia, short-chain or long-chain fatty acids) which could limit the extent of its conversion to glucose (Weekes et al. 1978; Demigné et al. 1986; Faulkner \& Pollock, 1986; Aiello \& Armentano, 1987). In turn, propionate may alter the rate of various metabolic pathways, especially ureogenesis or ketogenesis (Bush \& Milligan, 1971; Rattenbury et al. 1983; Emmanuel \& Kenelly, 1984; Demigné et al. 1986).

The pathway for glucose synthesis from propionate is well-established, but little is known of the control mechanisms which regulate this pathway in the ruminant liver. This point is important since the actual contribution of propionate to the overall synthesis of glucose in ruminants is still a matter of controversy: frequently, relatively low values (approximately $40 \%$ ) have been proposed and, as a result, some investigations did not account for all the glucose produced by the liver (Bergman et al. 1966; Judson et al. 1968; Wiltrout \& Satter, 1972; Reynolds \& Huntington, 1988). Quantification of the amount of glucose carbon derived from propionate involves various radiolabelled intermediates (particularly in the 
tricarboxylic acid cycle) which may be incompletely channelled towards gluconeogenesis. On the other hand, propionate- $\mathrm{C}$ atoms can also be replaced by $\mathrm{C}$ from other sources. Furthermore, it is conceivable that various metabolic factors may also affect, positively or negatively, propionate glucogenicity.

To address this problem, and to further investigate the effects of propionate on various metabolic pathways in the liver (ureogenesis, ketogenesis), the present study was carried out on isolated hepatocytes from sheep. This model affords estimation of the glucogenicity of the substrates under simplified metabolic conditions and is particularly useful for studies on the impact of substrates on intracellular metabolism.

\section{MATERIAL AND METHODS}

\section{Preparation of isolated hepatocytes}

Limousine sheep ( 6 months old) weighing about $50 \mathrm{~kg}$ were used; the animals were offered hay ad lib. plus $0.5 \mathrm{~kg} / \mathrm{d}$ of concentrate $(\mathrm{g} / \mathrm{kg}$ : barley 400 , maize 300 , soya seed cake 250 , and minerals). Male Wistar rats (IFFA-CREDO, L'Arbresle, France), each weighing about $180 \mathrm{~g}$, were used in some experiments for comparative purposes. They were fed ad lib. on commercial pellets (AO3, UAR, Villemoisson/Orge, France) containing $(\mathrm{g} / \mathrm{kg})$ : digestible protein 208, carbohydrate (essentially starch) 504, lipid 50 and cellulose 34 .

Sheep hepatocytes were prepared from portions of liver (about $30 \mathrm{~g}$, on the edge of the median lobe) removed immediately after slaughter in a local abattoir. The portal branch was cannulated, and the liver sample was perfused (by gravity using a portable infusion device) with a $\mathrm{Ca}^{2+}$-free Krebs buffer containing $0 \cdot 2 \mathrm{mM}$-EGTA at $38^{\circ}$, and transferred to the laboratory perfusion system (Masterflex pump, Cole Palmer, Chicago, Il., USA) within about $3 \mathrm{~min}$. All the subsequent steps of hepatocyte isolation from rat and sheep liver were similar, essentially as described by Krebs et al. (1974), except for (1) perfusion flow (about $3 \mathrm{ml} / \mathrm{g}$ liver) and amounts of collagenase (EC 3 .4.24.7) used (about 0.5 units $/ \mathrm{g}$ liver) that were in proportion to the weight of the liver sample, and (2) a two-step collagenase perfusion was used for sheep hepatocytes (step 1, $10 \mathrm{~min}$; step 2, about $20 \mathrm{~min}$ ). The cells were first separated from undigested debris by filtration through a $0.2 \mathrm{~mm}$ nylon mesh and were collected by centrifugation at $100 \mathrm{~g}$ for $90 \mathrm{~s}$.

Cell viability estimated by cell membrane refractoriness in phase-contrast microscopy or Trypan Blue exclusion, was over $95 \%$ for both rat and sheep hepatocytes. Incubations were performed under agitation at $37^{\circ}$ in a $27 \mathrm{~mm}$-bicarbonate Krebs-Henseleit buffer, pH $7 \cdot 4$ (Krebs et al. 1974) containing $20 \mathrm{~g}$ albumin (Boehringer, fraction V)/1 and cells were continuously gassed with carbogen (oxygen-carbon dioxide; $95: 5, \mathrm{v} / \mathrm{v}$ ).

\section{Metabolic studies}

Hepatocyte suspensions $(3 \mathrm{ml} ; 20-25 \mathrm{mg}$ fresh weight $/ \mathrm{ml})$ were taken in $10-\mathrm{ml}$ glass Erlenmayer flasks containing the substrates under study, and incubated at $37^{\circ}$ with gassing by carbogen. At the required intervals, portions $(0.5 \mathrm{ml})$ were withdrawn and immediately centrifuged $(8000 \mathrm{~g}, 10 \mathrm{~s})$ and the supernatant fraction subsequently analysed. For measurements of intracellular metabolites, two procedures were used on separate incubations: (1) $2 \mathrm{ml}$ cell suspension were centrifuged $(8000 \mathrm{~g}, 10 \mathrm{~s})$ and, after careful removal of the supernatant fraction, the tubes were immediately plunged in liquid nitrogen until further processing (for ATP, glucose-6-phosphate, phosphoenolpyruvate (PEP), malate and oxaloacetate), or (2) $500 \mu \mathrm{l}$ cell suspension were layered over $1500 \mu \mathrm{l}$ ice-cold Krebs buffer, centrifuged and treated as described later (p. 303), for determination of cellular amino acid. 


\section{Laboratory procedures}

Glucose, L-lactate, pyruvate, malate, oxaloacetate, glucose-6-phosphate, PEP, ATP and ammonia were determined spectrophotometrically on neutralized (potassium carbonate) supernatant fractions of perchloric extracts of blood or plasma (1 vol : 2 vol $0.6 \mathrm{M}$-perchloric acid) or of cell pellets $\left(120 \mu \mathrm{l} 0.4 \mathrm{M}-\mathrm{HClO}_{4}\right.$ for $40 \mathrm{mg}$ pellet) using standard enzymic methods (Siess et al. 1977). Urea was determined by a colorimetric method (Marsh et al. 1965) and propionate by gas-liquid chromatography after ethanolic extraction of the samples (Rémésy \& Demigné, 1974). Protein concentrations were measured using the bicinchoninic acid (BCA) protein reagent (Smith et al. 1985).

Glucose formation was measured using either unlabelled substrates (taking into account glucose release consecutive to glycogenolysis) or using labelled precursors. Labelled substrates are used (1) when there is an endogenous production of the precursor (L-lactate), (2) for substrates with a low glucogenicity which is difficult to detect by the chemical measurement of glucose (alanine, glutamine), or (3) for propionate in the presence of effectors which could distinctly affect its rate of utilization or conversion to glucose. The conversion of ${ }^{14} \mathrm{C}$-labelled glucogenic substrates into glucose was estimated after deproteinization of a $500 \mu \mathrm{l}$ supernatant fraction by $165 \mu \mathrm{l} 1 \cdot 2 \mathrm{M}-\mathrm{HClO}_{4}$, then neutralization by $165 \mu \mathrm{l} 0.75 \mathrm{M}-\mathrm{K}_{2} \mathrm{CO}_{3}$. The supernatant fraction was then applied to microcolumns of Dowex AG1-X8 (100-200 mesh, acetate form) for incubations with [2$\left.{ }^{14} \mathrm{C}\right]$ propionate or $\left[\mathrm{U}-{ }^{14} \mathrm{C}\right]$ lactate, or of Dowex AG50W-X2 (100-200 mesh, $\mathrm{H}^{+}$form) for incubations with $\left[\mathrm{U}^{14} \mathrm{C}\right]$ alanine or $\left[\mathrm{U}^{14} \mathrm{C}\right] \mathrm{glutamine}$. The columns were eluted four times each with $600 \mu \mathrm{l}$ deionized water, and the neutral fraction counted in InstaGel (Packard, Rungis, France).

Amino acids were determined after deproteinization of the samples by sulphosalicylic acid $(50 \mathrm{~g} / 1)$ containing $\alpha$-aminoadipic acid as an internal standard. The separation and the quantification of amino acids were performed by high performance liquid chromatography using lithium buffers on a Chromakon 500 (Kontron, Zürich, Switzerland) fitted with a $4.6 \times 250 \mathrm{~mm} \mathrm{MCl} \mathrm{Gel} \mathrm{column} \mathrm{(Mitsubishi,} \mathrm{Tokyo,} \mathrm{Japan)} \mathrm{using} \mathrm{post-column} \mathrm{deriv-}$ atization by ninhydrin.

Glutaminase (EC 3.5.1.2) activity was measured on intact mitochondria isolated from samples of liver, as previously described (Rémésy et al. 1988). Glutamine hydrolysis was determined according to Zaleski et al. (1986) in a medium containing various concentrations of L-glutamine from 0 to $20 \mathrm{~mm}$.

\section{Materials}

$\left[2-{ }^{14} \mathrm{C}\right]$ propionate was purchased from Amersham International plc (Amersham, Bucks, $\mathrm{UK})$ and $\left[\mathrm{U}-{ }^{14} \mathrm{C}\right]$ lactate, $\left[\mathrm{U}-{ }^{14} \mathrm{C}\right]$ alanine and $\left[\mathrm{U}-{ }^{14} \mathrm{C}\right]$ glutamine were from the CEA (Gif/Yvette, France). Collagenase ( $\mathrm{H}$ grade), bovine serum albumin (fraction V), enzymes and coenzymes were obtained from Boehringer (Meylan, France) and Dowex resins from Biorad (Richmond, CA, USA). The BCA protein reagent test was from Pierce (Interchim, Montluçon, France). Other reagents were commercially available products of the best analytical grade.

\section{Statistics}

The means for given variables were tested using a one-way analysis of variance. If a statistically significant result was obtained $(P<0.05)$ a priori contrasts of the groups were tested with least significance differences (LSD). For experiments with only two conditions, the Student's $t$ test was used (Snedecor \& Cochran, 1967). In all statistical tests we have chose to reject the null hypothesis at the $5 \%$ level $(P<0.05)$. 
Table 1. Gluconeogenesis from various substrates* in sheep and rat hepatocytes $\dagger$ (Mean values with their standard errors for no. of animals shown in parentheses; each assay was carried out in triplicate)

\begin{tabular}{|c|c|c|c|c|c|c|}
\hline & \multicolumn{6}{|c|}{ Glucose released $(\mu \mathrm{mol} / \mathrm{min}$ per $\mathrm{g}$ cell $)$} \\
\hline & \multicolumn{4}{|c|}{ Sheep } & \multirow{2}{*}{\multicolumn{2}{|c|}{ 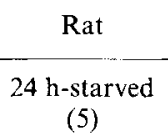 }} \\
\hline & \multicolumn{2}{|c|}{ Fed $(5) \ddagger$} & \multicolumn{2}{|c|}{$\begin{array}{c}72 \text { h-starved } \\
\text { (3) }\end{array}$} & & \\
\hline & Mean & SEM & Mean & SEM & Mean & SEM \\
\hline Propionate & $0 \cdot 73$ & $0 \cdot 06$ & 0.48 & $0-03$ & $0 \cdot 30$ & 0.03 \\
\hline Pyruvate & $0 \cdot 25$ & $0 \cdot 03$ & $0 \cdot 30$ & $0 \cdot 02$ & 0.60 & 0.06 \\
\hline Lactate & 0.03 & $0 \cdot 01$ & $0 \cdot 18$ & 0.02 & $0 \cdot 70$ & 0.06 \\
\hline Glycerol & $0 \cdot 15$ & $0 \cdot 03$ & $0 \cdot 17$ & 0.02 & $0 \cdot 65$ & $0 \cdot 05$ \\
\hline Dihydroxyacetone & $0 \cdot 39$ & 0.04 & n & & $1 \cdot 01$ & 0.09 \\
\hline Fructose & $0 \cdot 60$ & 0.05 & $\mathrm{n}$ & & $1 \cdot 44$ & $0 \cdot 12$ \\
\hline Sorbitol & 0.25 & 0.03 & $n$ & & $\mathrm{n}$ & \\
\hline Alanine & 0.05 & 001 & 0.07 & 0.02 & 0.40 & 0.03 \\
\hline Glutamine & 0.04 & 0.01 & 0.13 & 0.02 & $0 \cdot 14$ & 0.02 \\
\hline
\end{tabular}

nd, Not determined.

* Initial concentration $2.5 \mathrm{~mm}$.

$\uparrow$ For details of procedures, see p. 303.

$\doteqdot$ In these assays glycogenolysis was high, thus, glucose flux from propionate, lactate, alanine and glutamine were assessed in parallel using ${ }^{14} \mathrm{C}$-labelled substrates.

\section{RESULTS}

\section{Gluconeogenesis from propionate and other glucogenic substrates}

The substrates studied were generally used at the concentration of $2.5 \mathrm{~mm}$, rather than the concentrations of 5-10 $\mathrm{mM}$ frequently encountered, in order to limit some artifacts (for instance: ATP or free CoA depletion, maximal rate of metabolism with poor responsiveness to effectors, etc). To obviate the risks of extensive depletion of substrates under some conditions (incubations with 1.25 mM-propionate, for example), sampling was carried out at short intervals (every $10 \mathrm{~min}$ ) to check the linearity of the metabolic process. Nevertheless, the substrate concentrations were generally higher than the physiological concentrations (except for free fatty acids) : portal vein propionate is $0.2-0.5 \mathrm{~mm}$, L-lactate 0.4-1.0 mM, alanine 0.15 mm and glutamine about 0.2 $\mathrm{mm}$ (Bergman et al. 1966; Baird et al. 1980; Heitmann \& Bergman, 1980; Reynolds \& Huntington, 1988).

Glucose production by isolated sheep hepatocytes has been compared in fed or $72 \mathrm{~h}$ starved sheep, and in $24 \mathrm{~h}$-starved rats (Table 1). In sheep, propionate was the most effective glucogenic substrate (glucose flux, up to $1 \mu \mathrm{mol} / \mathrm{min}$ per $\mathrm{g}$ wet weight cell) but this flux was lower during starvation $(-34 \%)$. There was practically no gluconeogenesis from lactate in hepatocytes from fed sheep, but this process was detectable in hepatocytes from starved animals. Nevertheless, gluconeogenesis from lactate never represented more than one-third of gluconeogenesis from propionate and, in all conditions, lactate glucogenicity was much lower in sheep than in rat liver cells. In contrast, there was a noticeable conversion of pyruvate into glucose in hepatocytes from fed sheep (also lower than with rat hepatocytes). The glucogenicity of glycerol was low in ruminant hepatocytes, and dihydroxyacetone was more efficiently utilized than glycerol in both rat and sheep hepatocytes. Although they are not physiological substrates, fructose and sorbitol were efficiently converted to glucose by ruminant liver cells. Gluconeogenesis from alanine and 


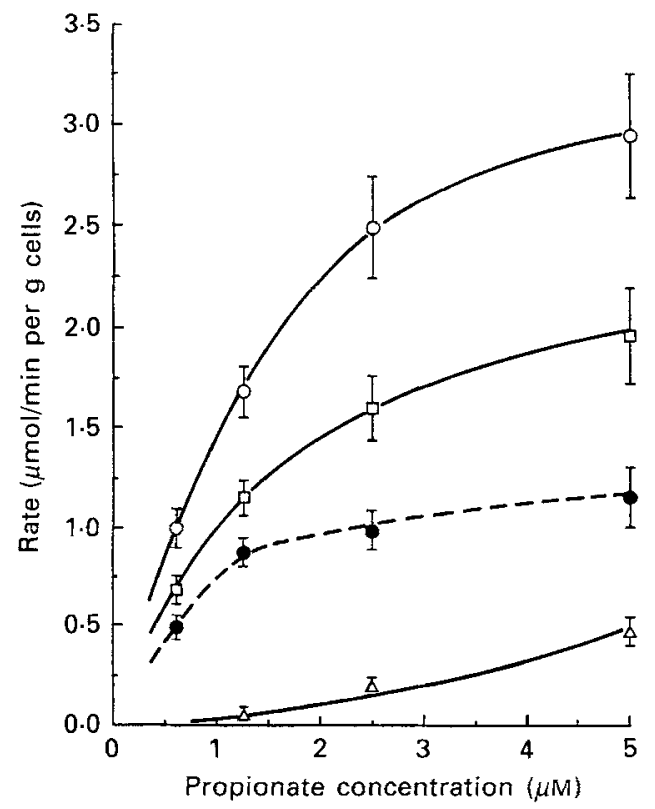

Fig. 1. Relationships between propionate concentration and the rate of propionate utilization $(\mathrm{O}-\mathrm{O})$ and of glucose $(\square-\square)$ and L-lactate production $(\triangle-\triangle)$ by sheep hepatocytes. For comparison, the rate of propionate utilization in rat hepatocytes is presented (--- The rate of glucose production is expressed as equivalent to three-carbon units produced/min per $\mathrm{g}$ cells. Values are means with their standard errors represented by vertical bars for four animals.

glutamine was very low in sheep hepatocytes whereas, for the same concentrations, alanine was effectively glucogenic in rat liver cells. There was a relatively more efficient conversion of glutamine into glucose (close to that of lactate or glycerol) in hepatocytes from starved sheep.

Fig. 1 shows the relationship between extracellular propionate concentrations and its rate of utilization and conversion to glucose. Hepatocytes from fed sheep had a very high capacity for propionate utilization (up to $3 \mu \mathrm{mol} / \mathrm{min}$ per $\mathrm{g}$ cell at $5 \mathrm{~mm}$ ) and for subsequent glucose synthesis. However, the percentage incorporation into glucose of propionate utilized was lower with increasing concentrations $(80 \%$ at $0.62 \mathrm{~mm} v .66 \%$ at $5 \mathrm{~mm}$ ) and a significant release of lactate could be observed for propionate concentrations higher than $2 \mathrm{~mm}$.

\section{Factors affecting gluconeogenesis from propionate}

Ammonia and butyrate are continuously absorbed from the rumen and, under certain circumstances, detectable amounts of ethanol may also be present in the portal vein. As shown in Table 2, ethanol turned out to be a potent inhibitor of propionate utilization and, to a higher degree, of gluconeogenesis (inhibition up to $75-80 \%$ ). The inhibitory effects were detectable at low concentrations of ethanol, in the range of $1 \mathrm{~mm}$. Furthermore, the percentage of inhibition by ethanol was as high at $2.5 \mathrm{~mm}$ as that at $1.25 \mathrm{~mm}$ propionate (values not shown). Low concentrations of ammonia (1 mM) did not affect propionate utilization, but ammonia was inhibitory at higher concentrations, conversion to glucose being particularly affected ( $-43 \%$ at $4 \mathrm{~mm}$-ammonia). As previously reported (Demigné et al. 1986), butyrate is an effective inhibitor of propionate utilization and conversion to 
Table 2. Effects of ethanol, ammonia and butyrate on the utilization of propionate and on the conversion of $1.25 \mathrm{~mm}-2\left[{ }^{14} \mathrm{C}\right]$ propionate into glucose by sheep hepatocytes

(Mean values with their standard errors for three animals (Expt 1) or two animals (Expt 2) in which each assay was carried out in triplicate)

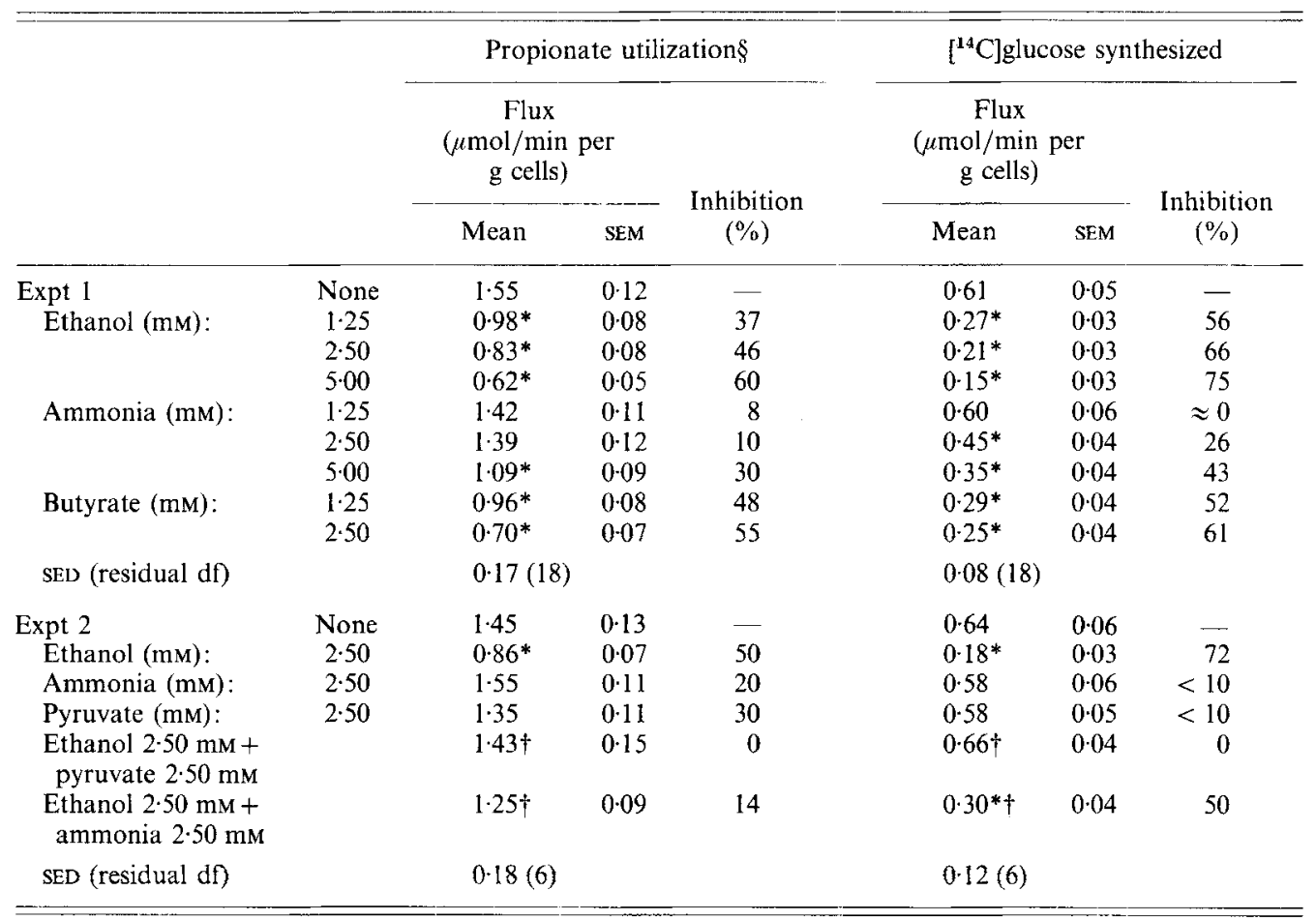

* Mean values were significantly different from those for hepatocytes incubated with propionate alone $(P<0.05)$.

$\dagger$ Mean values were significantly different from those for hepatocytes incubated with ethanol $(P<0.05)$.

\$ For details of procedures, see p. 303.

$\S$ Propionate utilization was measured by gas-liquid chromatography.

glucose. In Expt 2, the effects of substrates which could thwart the effect of ethanol via changes in cytosolic or mitochondrial redox state (namely pyruvate and ammonia) were investigated. In this experiment, neither $2.5 \mathrm{~mm}$-ammonia nor $2.5 \mathrm{~mm}$-pyruvate inhibited propionate metabolism. Pyruvate completely abolished the strong inhibitory effect of ethanol (72\% inhibition with ethanol alone) on gluconeogenesis from propionate. Ammonia restored a rate of propionate utilization that was not significantly different from the control value; however, glucose production was still markedly depressed $(-50 \%)$.

Table 3 presents the interactions between pyruvate, lactate and propionate metabolism. Lactate itself did not affect propionate metabolism (results not shown). The interferences between the pyruvate-yielding substrates (lactate, alanine, pyruvate) and propionate were investigated using pyruvate itself. As reported previously, pyruvate did not affect propionate metabolism, whereas pyruvate utilization was strongly reduced by propionate. Furthermore, under such conditions, most of the pyruvate used could be accounted for by lactate released in the incubation medium. Pyruvate uptake by ruminant hepatocytes was enhanced by even-chain fatty acids, resulting chiefly in lactate release (butyrate) or in glucose release (oleate). In contrast to propionate, pyruvate utilization was dramatically 
Table 3. Pyruvate metabolism and interactions with propionate, ethanol and fatty acids in isolated sheep hepatocytes $\$$

(Mean values with their standard errors for two animals in which each assay was carried out in triplicate)

\begin{tabular}{|c|c|c|c|c|c|c|c|c|}
\hline & \multicolumn{8}{|c|}{ Flux ( $\mu \mathrm{mol} / \mathrm{min}$ per g cells) } \\
\hline & \multicolumn{2}{|c|}{$\begin{array}{l}\text { Propionate } \\
\text { utilization }\end{array}$} & \multicolumn{2}{|c|}{$\begin{array}{c}\text { Pyruvate } \\
\text { utilization }\end{array}$} & \multicolumn{2}{|c|}{$\begin{array}{c}\text { Glucose } \\
\text { production }\end{array}$} & \multicolumn{2}{|c|}{$\begin{array}{c}\text { Lactate } \\
\text { production }\end{array}$} \\
\hline & Mean & SEM & Mean & SEM & Mean & SEM & Mean & SEM \\
\hline \multicolumn{9}{|l|}{ Pyruvate $2 \mathrm{~mm}$} \\
\hline None & & & 0.68 & $0 \cdot 04$ & 0.20 & 0.02 & $0 \cdot 25$ & $0 \cdot 03$ \\
\hline Propionate $2 \mathrm{~mm}$ & 1.98 & $0 \cdot 17$ & $0.27^{*}$ & 0.03 & $0.63^{*}$ & 0.06 & 0.40 & 0.04 \\
\hline Butyrate $2 \mathrm{~mm}$ & & & $1 \cdot 31^{*}$ & $0 \cdot 15$ & $0 \cdot 25$ & 0.03 & 0.62 & 0.05 \\
\hline Oleate I mM & & & $1 \cdot 12^{*}$ & $0 \cdot 10$ & $0.41^{*}$ & 0.04 & $0 \cdot 33$ & 0.03 \\
\hline Ethanol $2 \mathrm{~mm}$ & & & $2 \cdot 15^{*}$ & $0 \cdot 30$ & $0 \cdot 22$ & $0 \cdot 03$ & $1 \cdot 14$ & $0 \cdot 15$ \\
\hline \multicolumn{9}{|l|}{ Propionate $2 \mathrm{~mm}$} \\
\hline None & $2 \cdot 05$ & $0 \cdot 24$ & \multicolumn{2}{|c|}{-} & 0.65 & 0.05 & 0.18 & 0.02 \\
\hline Ethanol $2 \mathrm{~mm}$ & $1.02 \dagger$ & $0 \cdot 13$ & \multicolumn{2}{|c|}{-} & $0.24 \dagger$ & 0.03 & $0.52 \dagger$ & 0.05 \\
\hline $\begin{array}{c}\text { Ethanol } 2 \mathrm{~mm}+ \\
\text { pyruvate } 2 \mathrm{mM}\end{array}$ & 1.83 & $0 \cdot 16$ & 0.80 & 0.06 & $0.59 *$ & 0.05 & $0.90^{* \dagger}$ & $0 \cdot 10$ \\
\hline SED (residual df) & \multicolumn{2}{|l|}{$0.24(4)$} & \multicolumn{2}{|l|}{$0 \cdot 23(6)$} & \multicolumn{2}{|l|}{$0.07(8)$} & \multicolumn{2}{|l|}{$0.09(8)$} \\
\hline
\end{tabular}

* Mean values were significantly different from those for hepatocytes with pyruvate alone $(P<0.05)$.

$\uparrow$ Mean values were significantly different from those for hepatocytes with propionate alone $(P<0 \cdot 05)$

$\ddagger$ For details of procedures, see p. 303.

enhanced by ethanol, together with lactate release, whilst glucose production was unchange.

Table 4 presents the concentrations of intracellular metabolites involved in propionate metabolism. There was a trend to decreased intracellular ATP in the presence of propionate: 1.84 (SEM 0.23$) v .2 .54$ (SEM 0.33$) \mu \mathrm{mol} / \mathrm{g}$ cell in controls $(P=0.09)$. ATP was significantly depleted $(P<0.05)$ in the presence of propionate plus ammonia. Propionate metabolism brought about a considerable increase in the concentrations of malate and oxaloacetate in ruminant hepatocytes. The probable increase in the cellular redox status by ethanol amplified this phenomenon, leading to a large accumulation of intracellular malate (up to about $14.9 \mu \mathrm{mol} / \mathrm{g}$ cell) and to a concomitant drop of oxaloacetate. In contrast, ammonia rather counteracted malate accumulation. Aspartate present in high concentrations $(6-7 \mu \mathrm{mol} / \mathrm{g}$ cell) under basal conditions was poorly responsive to substrates, except to the addition of propionate plus ammonia. Glutamate was also present in high concentrations ( $3-5 \mu \mathrm{mol} / \mathrm{g}$ cell); it was not affected by propionate alone but markedly increased (up to $10-15 \mu \mathrm{mol} / \mathrm{g}$ cell) on the addition of ethanol or ammonia to propionate. The changes in PEP concentrations were approximately parallel to those of gluconeogenesis from propionate under most conditions, except in the presence of ethanol which elicited a drastic depletion of PEP whereas gluconeogenesis was not completely inhibited. Changes in glucose-6-phosphate concentrations essentially mirrored those of gluconeogenesis from propionate.

Interactions among gluconeogenesis, ureogenesis and amino acid metabolism

In ruminant hepatocytes, ureogenesis from ammonia levelled off at a relatively low ammonia concentration (about $2 \mathrm{mM}$ ); furthermore, ureogenesis was not responsive to the addition of $0.25 \mathrm{~mm}$-ornithine in the medium (results not shown). Table 5 shows that 


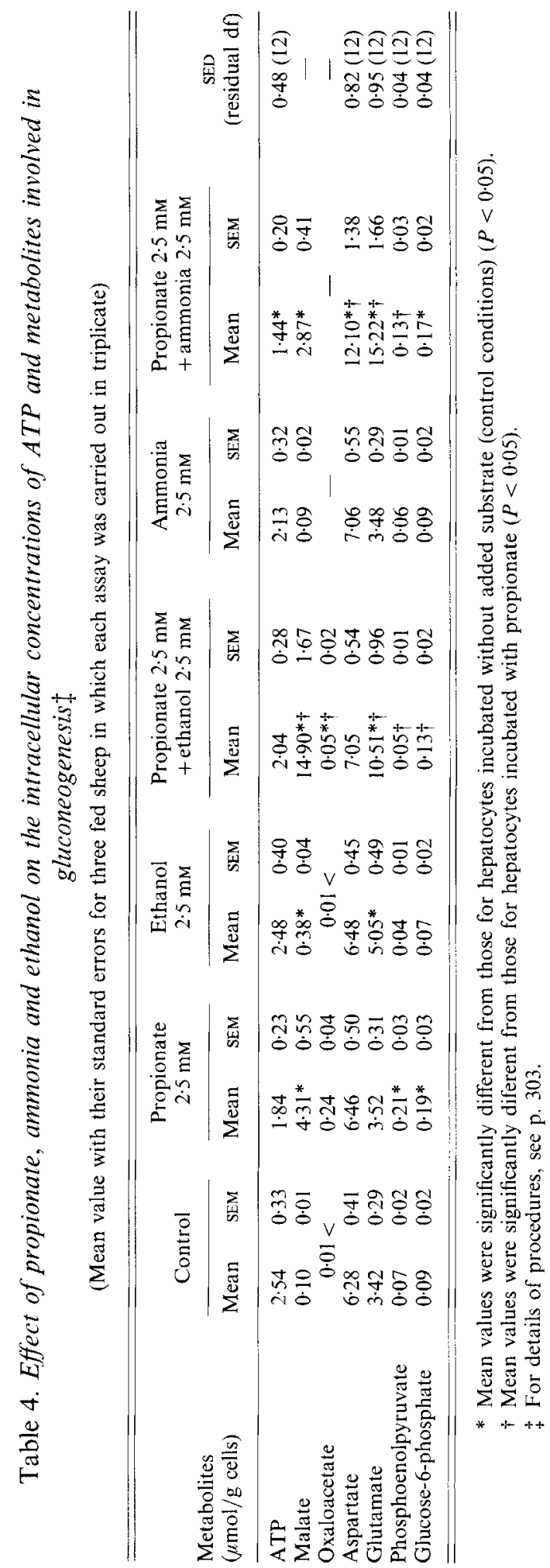


Table 5. Ureogenesis from ammonia in the presence of various substrates in hepatocytes from fed and starved sheep $\dagger$

(Mean values with their standard errors for three animals in which each assay was carried out in triplicate)

\begin{tabular}{|c|c|c|c|c|}
\hline \multirow[b]{2}{*}{ Addition } & \multicolumn{2}{|c|}{ Fed } & \multicolumn{2}{|c|}{72 h-starved } \\
\hline & Mean & SEM & Mean & SEM \\
\hline \multicolumn{5}{|l|}{ Ammonia $1.5 \mathrm{~mm}$} \\
\hline None & 0.41 & 0.03 & 0.25 & 003 \\
\hline Lactate $2.5 \mathrm{~mm}$ & 0.45 & 0.03 & $0.56^{*}$ & $0 \cdot 05$ \\
\hline Pyruvate $2.5 \mathrm{~mm}$ & 0.50 & 0.05 & \multicolumn{2}{|c|}{ nd } \\
\hline Propionate $2.5 \mathrm{~mm}$ & $0.65^{*}$ & 0.06 & $0.49^{*}$ & $0 \cdot 04$ \\
\hline Butyrate $2.5 \mathrm{~mm}$ & $0.77^{*}$ & 0.06 & $0.42 *$ & $0 \cdot 03$ \\
\hline $\begin{array}{l}\text { Propionate } 2.5 \mathrm{~mm}+ \\
\text { butyrate } 2.5 \mathrm{~mm}\end{array}$ & $0.80^{*}$ & $0 \cdot 07$ & $0.45^{*}$ & $0 \cdot 04$ \\
\hline Oleate $1 \mathrm{mM}$ & $0 \cdot 64^{*}$ & 0.05 & $0.42^{*}$ & $0 \cdot 04$ \\
\hline Octanoate $2 \mathrm{~mm}$ & $0 \cdot 7 l^{*}$ & $0 \cdot 06$ & $\mathrm{n}$ & \\
\hline SED (residual df): & \multicolumn{2}{|l|}{$0.09(12)$} & \multicolumn{2}{|c|}{$0.05(12)$} \\
\hline
\end{tabular}

nd, not determined.

* Mean values were significantly different from those for hepatocytes with $1.5 \mathrm{~mm}$-ammonia $\left(\mathrm{NH}_{4} \mathrm{Cl}\right)$ alone $(P<0.05)$.

$\uparrow$ For details of procedures, see p. 303.

propionate activated ureogenesis in vitro, as did butyrate, octanoate and oleate. Lactate and pyruvate were ineffective. In hepatocytes from starved sheep, basal ureogenesis was lower but, besides propionate and even-chain fatty acids, lactate was also stimulatory.

Ammonia in the incubation medium led to an increase in the intracellular concentrations of some amino acids, especially glutamate and alanine (Table 6). Propionate elicited a rise in the concentrations of serine and, to a lesser extent, of phosphoserine. In the presence of propionate and ammonia, there was an accumulation of glutamate and aspartate and a dramatic increase in phosphoserine and serine (together with an increase in glycine and alanine concentrations). On the addition of butyrate, there was an increase in glutamate and glycine, which was accentuated by the addition of ammonia. Modifications in phosphoserine and serine concentrations were less apparent than in the presence of propionate. Lactate did not affect intracellular amino acids but, in the presence of ammonia, lactate led to a noticeable rise of glutamate and alanine (values not shown).

When sheep hepatocytes were incubated in the presence of amino acids at nearphysiological concentrations (Table 7$)$, there was a noticeable release of urea $(0 \cdot 26 \mu \mathrm{mol} /$ min per cell) which appeared to be dissociated from gluconeogenesis $(0.05 \mu \mathrm{mol} / \mathrm{min}$ per $\mathrm{g}$ cell). The most readily utilized amino acids were glutamine, alanine, serine and, to a lesser extent, aromatic amino acids (not shown), glycine and threonine. It must be noted that glutamine was significantly utilized by ruminant hepatocytes at low extracellular concentrations (namely $0.5 \mathrm{~mm}$ ), in contrast to rat hepatocytes. In parallel, a net production of glutamate could be observed. Compared with values obtained with rat hepatocytes (Fafournoux et al. 1983; Rémésy et al. 1988), glutamine accumulation into ruminant liver cells was quite limited, together with relatively high basal concentrations of ornithine (about $0.30 \mu \mathrm{mol} / \mathrm{g}$ ). Most other glucogenic amino acids such as alanine, serine and glycine were concentrated into sheep liver cells (about 10-fold for alanine or glycine). In the presence of propionate in the medium, the intracellular concentrations of phosphoserine and serine were dramatically increased, up to 2.09 and $3.30 \mu \mathrm{mol} / \mathrm{g}$ cell respectively. Serine uptake by hepatocytes was depressed by $70 \%$ accordingly. Fur- 


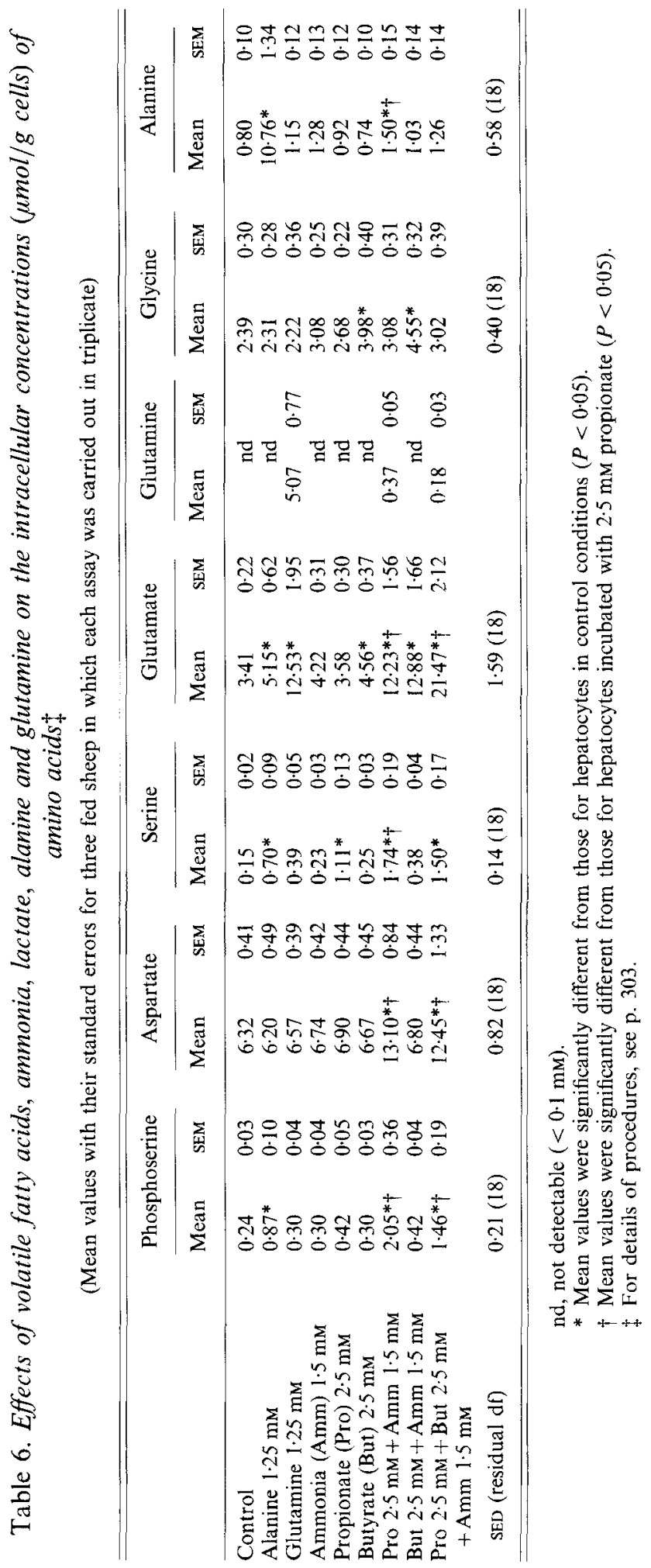




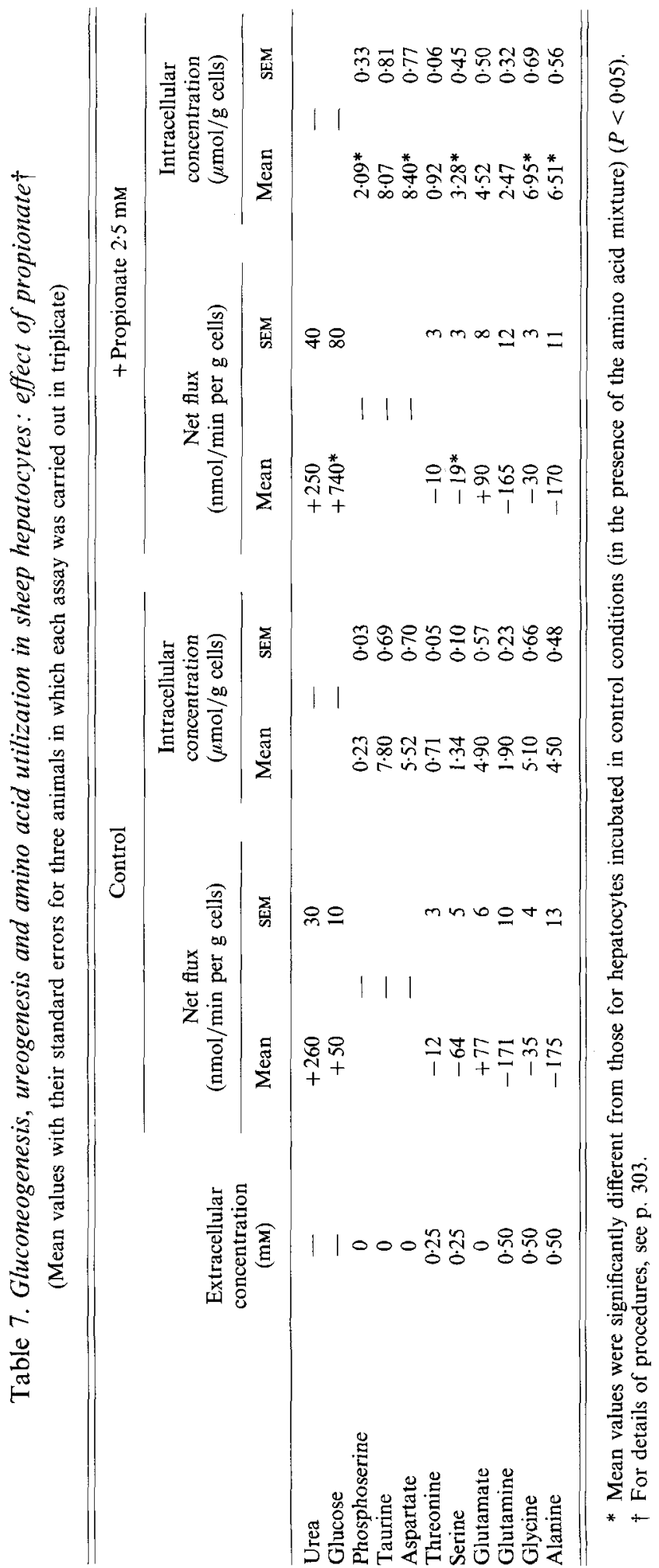




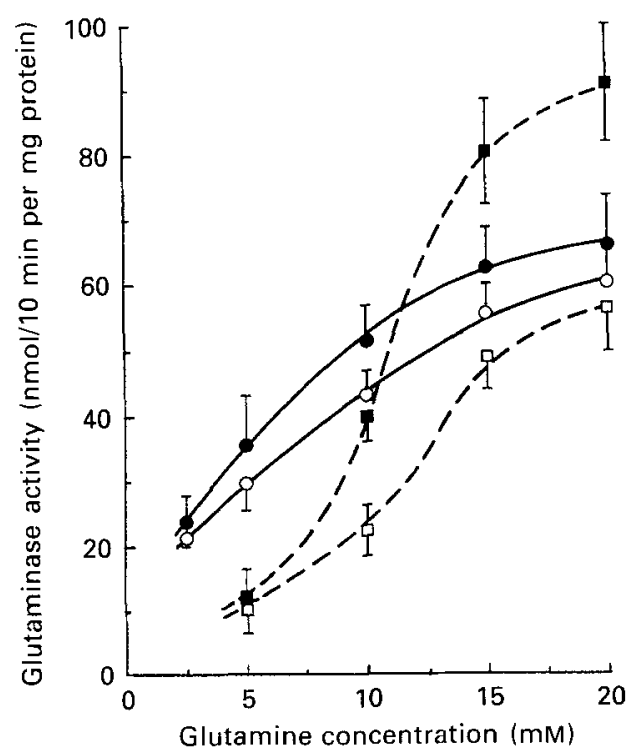

Fig. 2. Glutaminase (EC 3.5.1.2) activity in isolated mitochondria from sheep (--) and rat (--) liver. Values are means with their standard errors represented by vertical bars for three animals in which the assays were carried out in triplicate. Glutamine hydrolysis was measured with $(\mathbf{O}, \mathbf{a})$ or without $(O, \square)$ the addition of $0.5 \mathrm{~mm}$ ammonium chloride at $\mathrm{pH} 7 \cdot 4$ (corresponding to a concentration of the unionized ammonia form of $15 \mu \mathrm{M}$ ).

thermore, propionate enhanced the intracellular concentrations of glycine and alanine, but without altering their net uptake.

The relationship between glutaminase activity and glutamine concentrations in the medium is presented in Fig. 2, for mitochondria isolated from sheep and rat liver. The greatest activity was observed in mitochondria from rats, but the activity at low concentrations of glutamine $(2 \cdot 5-5.0 \mathrm{~mm})$ was higher in sheep mitochondria. Ammonia (equivalent to $15 \mu \mathrm{M}$ ) strikingly enhanced glutaminase activity in rat, but not in sheep, mitochondria. The reduction of the incubation medium $\mathrm{pH}$ to 7.0 depressed glutaminase activity in rat mitochondria as well as, although to a lesser extent, in sheep mitochondria (results not presented).

\section{DISCUSSION}

The flux of propionate determined with comparable concentrations of propionate (about $0.5 \mathrm{~mm}$ ) appears very similar in vivo and in vitro, in the range of $0.4-0.8 \mu \mathrm{mol} / \mathrm{min}$ per $\mathrm{g}$ liver tissue or g liver cells (Bergmann et al. 1966; Judson et al. 1968; Baird et al. 1980; Gill et al. 1985; Demigné et al. 1988; Veenhuizen et al. 1988). Nevertheless, it must be kept in mind that a variety of factors, including hormones, are present in vivo and may modulate the utilization of the various substrates. Compared with ruminants, rat hepatocytes have a lower capacity of propionate uptake and metabolism but they exhibit higher capacities of butyrate utilization (Demigné et al. 1986). It appears that gluconeogenesis from propionate is markedly depressed in hepatocytes from starved ruminants; this may reflect the decrease in propionyl-CoA carboxylase ( $E C 4.1 .1 .41)$ activity reported by Baird \& Young (1975); in addition, propionyl-CoA synthetase (EC 6.2.1.17) could be responsive to changes in the availability of propionate (Wahle et al. 1981).

Hepatocytes isolated from fed sheep failed to utilize lactate (present results; Harmon 
et al. 1984); a peculiarity also reported in vivo (Huntington et al. 1981; Naylor et al. 1984). The fact that pyruvate is more efficiently utilized than lactate suggests that the L-lactate dehydrogenase (EC 1 1 1 1.27) step could be rate-limiting for gluconeogenesis from lactate. In sheep, L-lactate dehydrogenase activity is relatively low $(160 \mathrm{nmol} / \mathrm{min}$ per $\mathrm{mg} 15000 \mathrm{~g}$ supernatant protein against about $1000 \mathrm{nmol} / \mathrm{min}$ per $\mathrm{mg}$ in the rat; Smith \& OsborneWhite, 1971); furthermore, the redox status in the cytosol could be unfavourable to lactate oxidation (Herriman \& Heitzman, 1978). Another controlling step for gluconeogenesis from pyruvate-yielding substrates is pyruvate carboxylase $(E C 6.4 .1 .1)$, which has a low activity in growing ruminants (Smith \& Walsh, 1982). Pyruvate carboxylase has been reported to be induced during pregnancy or lactation (Smith \& Walsh, 1982). It is noteworthy that oleate was very effective in channelling pyruvate towards glucose synthesis, apparently at the expense of lactate formation. A part of the PEP produced could be removed from the glucogenic pathway by pyruvate kinase (EC 2.7.1.40), since its activity is relatively high in sheep liver (Vernon et al. 1987), but the actual degree of activation, by dephosphorylation during hepatocyte isolation (Riou et al. 1985), is still poorly known in the ruminant. The rate of gluconeogenesis from glycerol, dihydroxyacetone and fructose was relatively low in sheep liver cells: since the overall activity of gluconeogenesis from $\mathrm{C}_{3}$ precursors is practically as high in sheep as in the rat, this could be ascribed to a lower activation of the previously mentioned substrates by sheep hepatocytes, possibly at the level of the specific kinases. In contrast to glucose, ruminant liver cells metabolized some fructose or sorbitol, which could be relevant for some clinical purposes (as antiketogenic agents).

Propionate metabolism is not dependent on pyruvate carboxylase but is dependent on mitochondrial PEP carboxykinase (EC 4.1.1.49), which is very active in ruminants (Ballard et al. 1969; Smith \& Osborne-White, 1971). Our results suggest that propionate might increase the NADH : NAD ratio in hepatocytes, which results in an accumulation of malate in ruminant hepatocytes. It must be noted that $2.5 \mathrm{~mm}$-propionate brought about a dramatic rise in both malate and oxaloacetate concentrations which suggests that the overall process of PEP synthesis may become rate-limiting. In the presence of high concentrations of propionate, the production of lactate could be mediated either by malic enzyme (of low activity in ruminants, Vernon et al. 1987) or by pyruvate kinase.

In vitro, a large part of the propionate is converted to glucose $(65-80 \%$, depending on propionate concentration). Similarly, Aiello \& Armentano (1987) found that the glucose: $\mathrm{CO}_{2}$ ratio obtained from $2\left[{ }^{14} \mathrm{C}\right]$ propionate was generally higher than 10 . This efficient conversion of propionate to glucose may reflect the fact that this requires only 4 ATP, against 6 ATP for lactate and 10 ATP for alanine. In vivo, a lower conversion of propionate to glucose might reflect reducing redox conditions prevailing in sheep liver mitochondria.

It appears that propionate utilization by sheep hepatocytes is inhibited by several metabolites: ethanol, butyrate and ammonia. Ethanol is the most potent inhibitor, effective at concentrations as low as $1 \mathrm{~mm}$. This observation has some agronomic relevance since ruminants may consume on occasions silages containing up to $40 \mathrm{~g}$ ethanol $/ \mathrm{kg}$ dry matter. A large part escapes bacterial metabolism and is absorbed; information about ethanol concentration in the portal vein is still lacking but it may be assumed that concentrations in the range of 1-2 mM could be attained with such silages. The inhibitory effect of ethanol could be strengthened by the fact that propionate itself leads to malate accumulation. That ethanol inhibition is mediated by a rise in the cellular NADH: NAD ratio is supported by the restoration of propionate utilization on the addition of pyruvate. The fact that gluconeogenesis is affected more than propionate utilization itself raises the question of the metabolic fate of propionate-C escaping gluconeogenesis. A large part is likely to be 
transferred to organic acids, including lactate. This is reminiscent of the effect of ethanol on pyruvate metabolism.

An inhibitory effect of butyrate on gluconeogenesis from propionate has been previously reported (Demigné et al. 1986; Aiello \& Armentano, 1987) and contrasts with the activating effects of butyrate on pyruvate utilization. Butyrate is unlikely to act via an enhanced supply of energy since octanoate or oleate had no effect on propionate metabolism (results not shown). Butyrate may compete with propionate for activation to acyl-CoA in the mitochondria (Ricks \& Cook, 1981), but propionate metabolism could also be inhibited by butyrate at a site independent of the activation reaction (Aiello \& Armentano, 1987). Some other short-chain fatty acids (isobutyrate, valerate, 2-methylbutyrate) may, on the other hand, channel propionate- $\mathrm{C}$ towards gluconeogenesis rather than to oxidation (Aiello et al. 1989). Furthermore, propionate is a potent inhibitor of pyruvate utilization (present results; Smith, 1971), possibly by inhibition of pyruvate carboxylase by the various CoAesters appearing during propionate metabolism (propionyl CoA, methylmalonyl-CoA, succinyl CoA).

Inhibitory effects of ammonia on propionate metabolism require relatively high concentrations ( $>2 \mathrm{~mm}$ ) which bring about a marked depletion of cellular ATP together with an accumulation of aspartate and glutamate, probably at the expense of oxaloacetate and 2-oxoglutarate. In contrast, amino acids did not inhibit gluconeogenesis from propionate. Stimulation of ureogenesis by propionate, butyrate or fatty acids may arise from energy provision or from alterations of some intermediates of the urea cycle. Propionate stimulated ureogenesis from ammonia (but not from amino acids) whilst cellular ATP was depleted. Furthermore, propionate, butyrate and fatty acids (values not presented) considerably enhanced the intracellular concentrations of glutamate (and aspartate with propionate). These results contrast with the inhibitory effects of propionate on ureogenesis reported in the rat (Cathelineau et al. 1979) and in sheep (Rattenbury et al. 1983).

The concomitant availability of large amounts of amino groups and of organic acids may lead to the synthesis of various amino acids, as shown in the rat (Brosnan \& Williamson, 1974). However, there are particular effects of propionate in ruminants, especially the concomitant rise in the cellular concentrations of phosphoserine and serine. In the rat, the biosynthesis of serine is generally coupled to a high glycolytic activity (along with induction of certain key-enzymes such as 3-phosphoglycerate dehydrogenase $(E C 1.1 .1 .95)$ and phosphoserine aminotransferase (EC 2.6.1.52); (Snell, 1980). In contrast, serine synthesis in ruminant hepatocytes seems to accompany a high rate of gluconeogenesis (high concentrations of PEP); however, a possible effect of propionate on serine catabolism could not be ruled out. It is noteworthy that the synthesis of phosphoserine and serine also depends on the availability of the $\mathrm{NH}_{2}$ group, whether provided by ammonia or amino acids (alanine for instance). The physiological significance of this process is still to be ascertained, however it is established that serine is involved in the synthesis of various classes of phospholipids and recent works shows that the biosynthesis of long-chain bases (such as sphingosine) is stimulated by a high availability of serine (Messmer et al. 1989). This feature could provide an explanation of the antisteatosic effects of propionate in ruminants.

Sheep hepatocytes can catabolize certain amino acids with, however, some peculiarities compared with the rat. In hepatocytes from fed ruminants, there is a similar utilization of alanine and glutamine, whereas in rat hepatocytes alanine is more efficiently utilized than glutamine (Lund \& Watford, 1976; Hayes \& McGivan, 1982; Rémésy et al. 1988). The rate of alanine or glutamine utilization plateaued (about $0.3 \mu \mathrm{mol} / \mathrm{min}$ per g cell) at extracellular concentrations of about $1 \mathrm{~mm}$. It is noteworthy that glutamine (which yields, like 
propionate, an intermediate of the Krebs cycle) is not efficiently glucogenic: for a rate of glutamine utilization of $0.35 \mu \mathrm{mol} / \mathrm{min}$ per g cell at $2.5 \mathrm{~mm}$, only $0.04 \mu \mathrm{mol} / \mathrm{min}$ per $\mathrm{g}$ cell glucose was produced in vitro. This process appears more efficient during starvation. This low conversion of glutamine into glucose could reflect the fact that gluconeogenesis, when coupled to ureogenesis, is an energy-consuming process. However, addition of fatty acids failed to stimulate gluconeogenesis from glutamine or alanine (results not shown). Another explanation is that glutamine may give rise to other amino acids, especially glutamate; glutamate accumulates in liver cells incubated in the presence of glutamine, and a part may be released in the external medium. Both glutamine catabolism and glutaminase activity are relatively high in ruminant liver cells under basal conditions, namely in the absence of effectors of glutamine catabolism. Furthermore, it appears that ammonia has little effect on glutamine metabolism in ruminant hepatocytes whereas it is a potent activator of glutaminolysis in rat liver cells (Lund \& Watford, 1976).

Ruminant hepatocytes are also characterized by high intracellular concentrations of glutamate, aspartate and glycine. When hepatocytes were incubated in the presence of glutamine, a considerable accumulation of glutamate was observed whereas that of glutamine was quite limited, in contrast with the rat (Rémésy et al. 1988). Under such conditions (or when intracellular glutamate is elevated in the presence of ammonia + propionate + butyrate), there is a net release of glutamate by ruminant liver cells, a phenomenon also observed in vivo (Heitmann \& Bergman, 1980). As suggested previously, glutamate release by liver cells may lessen the contribution of certain amino acids to gluconeogenesis. Glycine accumulation is also a characteristic feature of ruminant hepatocytes. Such an accumulation has been observed in blood plasma and in the liver of ketotic ewes (Demigné et al. 1988).

In conclusion, the present work emphasizes the high capacity of sheep hepatocytes to metabolize propionate (chiefly towards glucose), compared with liver cells of simplestomached species. However, it appears that propionate metabolism is subject to inhibition by various metabolites present in portal blood (butyrate, ammonia, occasionally ethanol) and that there may be complex interactions between these effectors. Changes in the redox status of the cytosolic or mitochondrial compartments are likely to modulate the conversion of propionate to glucose, which seems rather depressed under conditions of elevated NADH: NAD ratios. In turn, it appears that propionate is a potent effector of a variety of metabolic processes including not only gluconeogenesis, ureogenesis and ketogenesis but also the metabolism of certain amino acids such as phosphoserine and serine.

\section{REFERENCES}

Aiello, R. J. \& Armentano, L. E. (1987). Effects of volatile fatty acids on propionate metabolism and gluconeogenesis in caprine hepatocytes. Journal of Dairy Science 70, 2504-2510.

Aiello, R. J., Armentano, L. E., Bertics, S. J. \& Murphy, A. T. (1989). Volatile fatty acid uptake and propionate metabolism in ruminant hepatocytes. Journal of Dairy Science 72, 942-949.

Baird, G. D., Lomax, M. A., Symonds, H. W. \& Shaw, S. R. (1980). Net hepatic and splanchnic metabolism of lactate, pyruvate and propionate in dairy cows in vivo in relation to lactation and nutrient supply. Biochemical Journal 186, 47-57.

Baird, G. D. \& Young, J. L. (1975). The response of the key gluconeogenic enzymes in bovine liver to various dietary and hormonal regimes. Journal of Agricultural Science, Cambridge 84, 227-230.

Ballard, F. J., Hanson, R. W. \& Kronfeld, D. S. (1969). Gluconeogenesis and lipogenesis in tissues from ruminant and non-ruminant animals. Federation Proceedings 28, 218-231.

Bergman, E. N., Roe, E. R. \& Kon, K. (1966). Quantitative aspects of propionate metabolism and gluconeogenesis in sheep. American Journal of Physiology 211, 793-799.

Brosnan, J. T. \& Williamson, D. H. (1974). Mechanism of the formation of alanine and aspartate in rat liver in vivo after administration of ammonium chloride. Biochemical Journal 138, 459-462.

Bush, R. S. \& Milligan, L. P. (1971). Study of the mechanism of inhibition of ketogenesis by propionate in bovine liver. Canadian Journal of Animal Science 51, 121-127. 
Cathelineau, L., Petit, F. P., Coudé, F. X. \& Kamoun, P. P. (I979). Effect of propionate and pyruvate on citrulline synthesis and ATP content in rat liver mitochondria. Biochemical and Biophysical Research Communications 90. 327-332.

Demigné, C., Yacoub, C., Morand, C. \& Rémésy, C. (1988). Orientation of the intermediary metabolism in ruminants (in French). Reproduction, Nutrition, Développement 28, $1-17$.

Demigné, C., Yacoub, C.. Rémésy, C. \& Fafournoux, P. (1986). Propionate and butyrate metabolism in rat or sheep hepatocytes. Biochimica et Biophysica Acta 875, 535-542.

Emmanuel, B. \& Kenelly, J J. (1984). Effect of propionic acid on ketogenesis in lactating sheep fed restricted rations or deprived of food. Journal of Dairy Science 67, 344-350.

Fafournoux, P., Rémésy, C. \& Demigné, C. (1983), Control of alanine metabolism in rat liver by transport processes or cellular metabolism. Biochemical Journal 210, 645-652.

Faulkner, A. \& Pollock, H. T. (1986). Propionate metabolism and its regulation by fatty acids in ovine hepatocytes. Comparative Biochemistry and Physiology 84 B, 559-563.

Gill, W., Mitchell, G. E., Boling, J. A., Tucker, R. E., Schelling, G. T., \& DeGregorio, R. M. (1985). Glucagon influence on gluconeogenesis and oxidation of propionic acid and threonine by perfused ovine liver. Journal of Dairy Science 68, 28862894.

Harmon, D. L., Britton, R. A. \& Prior, R. L. (1984). In vitro rates of oxidation and gluconeogenesis from L(+)and $\mathrm{O}(-)$-lactate in bovine tissues. Comparative Biochemistry and Physiology $77 \mathrm{~B}, 365-368$.

Hayes, M. R. \& McGivan, J. D. (1982). Differential effects of starvation on alanine and glutamine transport in isolated rat hepatocytes. Biochemical Journal 204, 365-368.

Heitmann, R. N. \& Bergman, E. N. (1980). Integration of amino acid metabolism in sheep: effects of fasting and acidosis. American Journal of Physiology 239, E248-E254.

Herriman, I. D. \& Heitzman, R. J. (1978). The effects of fasting on the concentrations of intermediate metabolites in the blood and hepatic tissues of pregnant and non-pregnant ewes. Journal of Agricultural Science $\mathbf{9 0}$, 579-585.

Huntington, G. B., Prior, R. L. \& Britton, R. A. (1981). Glucose and lactate absorption and metabolic interrelationship in steers changed from low to high concentrate diets. Journal of Nutrition 111, 1164-1172.

Judson, G. J., Anderson, E. E., Luick, J. R. \& Leng, R. A. (1968). The contribution of propionate to glucose synthesis in sheep given different diets of different grain contents. British Journal of Nutrition 22, 69-74.

Krebs, H. A., Cornell, N. W, Lund, P. \& Hems, R. (1974). Isolated liver cells as an experimentai material. In Regulation of Hepatic Metabolism, pp. 726-750 [F. Lundquist and N. Tygstrup, editors]. Copenhagen: Munksgaard.

Lund, P. \& Watford, M. (1976). Glutamine as a precursor of urea. In The Urea Cycle, pp. 479-491 [S. Grisolia, R. Baguena and F. Mayor, editors]. London: J. Wiley.

Martin, R. J., Wilson, L. L., Crown, R. L. \& Sink, J. D. (1973). Effects of fasting and diet on enzyme profiles in ovine liver and adipose tissue. Journal of Animal Science 36, 101-106.

Marsh, D. J., Frasier, B. \& Decter, J. (1965). Measurements of urea concentration in nanoliter specimens of renal fluid and capillary blood. Analytical Biochemistry 70, 24I-250.

Messmer, T. O., Wang, E., Stevens, V. L. \& Merrill, A. H. (1989). Sphingolipid biosynthesis by rat liver cells: effects of serine, fatty acids and lipoproteins. Journal of Nutrition 119, 534-538.

Naylor, J. M., Kronfeld, D. S., Freeman, D. E. \& Richardson, D. (1984). Hepatic and extrahepatic lactate metabolism in sheep: effect of lactate loading and pH. American Joumal of Physiology 247, E747-E755.

Rattenbury, J. M., Kenwright, A. M., Withers, C. J. \& Shepherd, D. A. L. (1983). Effect of propionic acid on urea synthesis by sheep liver. Research in Veterinary Science 35, 61-63.

Rémésy, C. \& Demigné, C. (1974). Determination of volatile fatty acids in plasma after ethanolic extraction. Biochemical Journal 141, 85-91.

Rémésy, C., Morand, C., Demigné, C. \& Fafournoux, P. (1988). Control of hepatic utilization of glutamine by transport processes or cellular metabolism in rats fed a high protein diet. Journal of Nutrition 118, 569-578.

Reynolds, P. J. \& Huntington, G. B. (1988). Net portal absorption of volatile fatty acids and L(+)-lactate by lactating Holstein cows. Journal of Dairy Science 71, 124-133.

Ricks, C. A. \& Cook, R. M. (1981). Regulation of volatile fatty acid uptake by mitochondrial acylCoA synthetases of bovine liver. Joumal of Dairy Science 64, 2324-2335.

Riou, J. P., Audigier, C., Laville, M., Pigeon, P. \& Mornex, R. (1985). Dephosphorylation of L-pyruvate kinase during rat liver hepatocyte isolation. Archives of Biochemistry and Biophysics 236, 321-327.

Siess, E. A., Brocks, D. G., Lattke, H. K. \& Wieland, O. H. (1977). Effect of glucagon on metabolite compartmentation in isolated rat liver cells during gluconeogenesis from lactate. Biochemical Journal $\mathbf{1 6 6}$, 225-235.

Smith, P. K., Krohn, R. I., Hermanson, G. T., Mallia, A. K., Gartner, F. H., Provenzano, M. D., Fujimoto, E. H., Goeke, N. M., Olson, B. J. \& Klenk, D. C. (1985). Measurement of protein using bicinchoninic acid. Analytical Biochemistry 150, 76-85.

Smith, R. M. (1971). Interactions of acetate, propionate and butyrate in sheep liver mitochondria. Biochemical Journal 124, 877-881.

Smith, R. M. \& Osborne-White, W. S. (1971). Synthesis of phosphoenolpyruvate from propionate in sheep liver. Biochemical Journal 124, 867-876. 
Smith, R. W. \& Walsh, A. (1982). Effects of pregnancy and lactation on the activities in sheep liver of some enzymes of glucose metabolism. Journal of Agricultural Science, Cambridge 98, 563-565.

Snedecor, G. \& Cochran, W. (1967). Méthodes Statisques, translation of the 6th ed. Paris: Association de Coordination Technique Agricole.

Snell, K. (1980). Liver enzymes of serine metabolism during neonatal development of the rat. Biochemical Journal $190,451-455$

Veenhuizen, J. J., Russell, R. W. \& Young, J. W. (1988). Kinetics of metabolism of glucose, propionate and $\mathrm{CO}_{2}$ in stecrs as affected by injecting phlorizin and feeding propionate. Journal of Nutrition 118, 1366-1375.

Vernon, R. G., Faulkner, A., Finley, E., Pollock, H. \& Taylor, E. (1987). Enzymes of glucose and fatty acid metabolism of liver, kidney, skeletal muscle, adipose tissue and mammary gland of lactating and non-lactating sheep. Journal of Animal Science 64, 1395-1411.

Wahle, K. W. J., Livesey, C. T. \& Scaife, J. R. (1981). Effect of dietary monensin on aspects of propionate metabolism and lipogenesis in sheep. In Metabolic Disorders in Farm Animals pp. 131-134 [D. Giesecke, G. Dirksen and M. Stangassinger, editors]. Münich : Fotodruck.

Weekes, T. E. C., Richardson, R. 1. \& Geddes, N. (1978). The effect of ammonia on gluconeogenesis by isolated sheep liver cells. Proceedings of the Nutrition Society 38, 3A.

Wiltrout, D. W. \& Satter, L. D. (1972). Contribution of propionate to glucose synthesis in the lactating and the non-lactating cow. Joumal of Dairy Science 55, 307-317.

Zaleski, J., Wilson, D. F. \& Erecinska, M. (1986). $\beta$-2-Aminobicylo-(2.2.1)-heptane-2-carboxylic acid. A new activator of glutaminase in intact rat liver mitochondria. Journal of Biological Chemistry 216, 14091-14094. 